\title{
UPACARA ADAT MAMAPAS LEWU (STUDI KASUS DI KOTA KASONGAN KALIMANTAN TENGAH)
}

\author{
Erik Chilwanto, Safna, Mutiara, Gusmadi Rahmad, Offeny, \& Ahmad Saefulloh \\ Universitas Palangka Raya \\ erikchilwanto@gmail.com
}

\begin{abstract}
Abstrak:
Penelitian ini bertujuan untuk mengetahui bagaimana tata cara upacara mamapas lewu, fungsi serta maknanya bagi kehidupan masyarakat di Kota Kasongan Kalimantan Tengah. Metode penelitian yang digunakan adalah kualitatif deskriptif. Sumber data yaitu data primer dan data sekunder. Teknik pengumpulan data menggunakan wawancara, observasi, dan dokumentasi sedangkan teknik analisis data menggunakan pengumpulan data (data collection), reduksi data, penyajian data, dan penarikan kesimpulan. Mamapas lewu adalah salah satu implementasi ajaran Hindu kaharingan dalam mewujudkan rasa hormat, dan terima kasih kepada Tuhan (Ranying Hatalla Langit) karena telah menjaga alam dan kampung dari marabahaya. Mamapas Lewu dilakukan karena adanya suatu peristiwa atau kejadian yang berhubungan dengan pembunuhan, ancaman keselamatan, atau kejadian di timpa musibah penyakit yang menimpa seluruh penduduk atau kota. Upacara ini bertujuan untuk membersihkan alam dan lingkungan hidup (petak danum) beserta segala isinya dari berbagai bahaya dan celaka agar diberikan keberuntungan, keselamatan, umur yang panjang, rejeki yang melimpah serta ketentraman lahir batin kepada seluruh penduduk kampung atau kota.
\end{abstract}

Kata Kunci: Upacara Adat Dayak; Mamapas Lewu; Kota Kasongan

\section{Abstract:}

This study aims to find out how the mamapas lewu ceremony is performed, its function and meaning for human life in Kasongan City, Central Kalimantan.The research method used is descriptive qualitative. Data sources are primary data and secondary data. Data collection techniques use interviews, observation, and documentation, while data analysis techniques use data collection, data reduction, data presentation, and drawing conclusions. Mamapas lewu is one of the implementations of Hindu kaharingan teachings in realizing respect, and thanks to God (Ranying Hatalla Langit) for protecting nature and the village from harm. Mamapas Lewu is carried out because of an incident or incidents related to murder, a threat to safety, or an incident that occurs when a disaster strikes the entire population or the city. This activity aims to clean nature and the environment (Petak Danum) and all its contents from various dangers and misfortunes in order to be given luck, safety, long life, abundant fortune and inner and outer peace to all residents of the village or city.

Keywords: Dayak Tradisional Ceremony; Mamapas Lewu; Kasongan city

\section{PENDAHULUAN}

Mamapas lewu adalah sebuah ritual yang dijalankan oleh umat penganut agama kaharingan Provinsi Kalimantan tengah, kegiatan ini bertujuan untuk membersihkan Alam dan lingkungan hidup ( petak danum ) beserta segala isi nya dari berbagai marabahya, sial wabah penyakit ( rutas pali ) dan sebagainya. Mamapas lewu juga merupakan perwujudan tatanan kehidupan masyarakat dayak dalam berinteraksi dengan komunitas sesama yang merupakan gambaran kehidupan suku dayak dalam menjalin persatuan ( falsafah rumah betang ) acara ini juga untuk menjalin silahturami antara sesama warga sekaligus merupakan perwujudan dari kerukunan antar umat beragama. Kegiatan ini disimbolkan dengan mengundang masyarakat untuk makan dan minum bersama dalam suasana kegembiraan. Acara ini juga diisi dengan “ mamapas lewu" yang bermakna membersihkan kampung atau daerah dari 
hal hal yang buruk. Banyak pula yang memakai ritual ini sebagai tolak bala dengan harapan masyarakat dan daerah ini terhindar dari bala bencana. Meski merupaka ritual agama hindu kaharingan, namun tujuan kegiatan ini ditujukan untuk seluruh masyarakat. Bahkan saat acara, seluruh masyarakat diundang tanpa membeda bedakan suku, dikatakan mamapas lewu ini mempunyai tujuan untuk memulihkan kesiimbangan hubungan antara manusia dan Tuhan, serta manusia dengan alam sekitar agar terhindar dari marabahaya dan marabencana, hal ini juga sebagai upaya melestarikan nilai nilai religius yang melekat pada masyarakat kalteng (Rogate, 2016).

Ritual ini berfungsi sebagai sebagai aktivitas untuk menimbulkan kembali semangat kehidupan sosial dalam setiap masyarakat secara berulang, dengan interval waktu tertentu, memerlukan hal yang disebut regenerasi semangat kehidupan sosial seperti itu. Hal itu disebabkan karena selalu ada saat saat dimana semangat kehidupan sosial menurun dan akibatnya akan timbul kelesuan dalam masyarakat. Mengapa upacara tersebut dilakukan yaitu untuk mengucapakan rasa terimakasih kepada ranying hatalla serta roh suci leluhur karena telah menjaga dan memberikan keselamatan kepada masyarakat yang tinggal dikampung tersebut.

Suku Dayak merupakan salah satu suku yang ada di Indonesia yang tinggal di Pulau Kalimantan.Suku Dayak sendiri masih dibagi lagi menjadi ratusan sub-suku berdasarkan tempat tinggal mereka. Biasanya setiap sub-suku Dayak mengambil nama suku mereka dari nama sungai yang ada di sekitar mereka atau tempat yang mereka diami (Iper, 1999).

Setiap Suku Dayak sendiri memiliki pemimpin yang mereka taati dan setia pada pemimpin yang telah mereka akui sendiri (Nurgiansah, 2020). Pemimpin yang diakui oleh masyarakat Suku Dayak bukanlah seorang yang hanya memberikan perintah atau menerima pelayanan lebih dari masyarakat, melainkan pemimpin yang mampu mengayomi dan mengenal masyarakatnya dengan baik.

Asal mula Suku Dayak di Kalimantan adalah migrasi Bangsa Cina dari Provinsi Yunnan di Cina Selatam pada 3000-1500 SM (sebelum masehi) ke Pulau Kalimantan.Sebelum datang ke wilayah Indonesia, mereka mengembara terlebih dahulu ke Tumasik dan semenanjung Melayu.Suku Dayak tidak hanya satu, melainkan terbagi lagi menjadi sub-suku yang jumlahnya 700 hingga 800 atau bahkan lebih.

Ciri khas watak orang Dayak adalah "mamut menteng ureh mameh", baik lakilaki maupun perempuan sama saja. Mamut menteng artinya gagah perkasa, ureh yang berarti giat, dan mameh yang artinya suka mengalah.Selain itu, Suku Dayak juga memiliki motto kehidupan warisan leluhur, yaitu "Isen Mulang" yang artinya adalah pantang menyerah.Motto ini dipegang oleh setiap masyarakat Suku Dayak, tidak terkecuali pemimpin mereka.

Selain melalui mitologi dan legenda, cara yang dapat dilakukan untuk mengenal kesadaran sejarah pada masyarakat yang belum mengenal tulisan yaitu melalui upacara. Upacara yang dimaksud bukanlah upacara dalam pengertian upacara yang formal sering dilakukan, seperti upacara penghormatan bendera.Melacak melalui upacara, yaitu upacara yang pada umumnya memiliki nilai sakral oleh masyarakat pendukung kebudayaan tersebut.Upacara adalah serangkaian tindakan atau perbuatan yang terikat pada aturan tertentu berdasarkan adat istiadat, agama, dan kepercayaan. Jenis upacara dalam dalam kehidupa masyarakat, antara lain, upacara penguburan, upacara perkawinan, dan upacara pengukuhan 
kepala suku. Upacara adat adalah bentuk kebaktian masyarakat Dayak Ngaju terhadap Ranying Hatalla (Tuhan), dewadewa, roh nenek moyang atau mahluk halus lainnya,dan dalam Usahanya untuk berkomunikasi dengan Tuhan dan mahluk gaib lainnya untuk memperolehkehidupan yang sejahtera (Nurgiansah, 2021b).

Upacara adat masyarakat Dayak Ngaju adalah jalan yang dilakukan untuk berkomunikasi dengan Ranying Hatalla (Tuhan). Dari sepuluh upacara adat Dayak Ngaju terdapat beberapa simbol, yaitu:

a. Upacara tiwah terdapat 18 simbol, yaitu 14 nonverbal, dan 4 simbolverbal

b. Upacara perkawinan terdapat 47 simbol, yaitu 44 simbol nonverbal, dan 3 simbol verbal

c. Upacara manajah antang terdapat 12 simbol, yaitu 10 simbol nonverbal, dan 2 simbol verbal

d. Upacara kematian terdapat 9 simbol, yaitu tujuh simbol nonverbal, dan2 simbol verbal

e. Upacara mapalas terdapat 11 simbol, yaitu 10 simbol nonverbal, dan satu simbol verbal

f. Upacara kehamilan terdapatlima simbol nonverbal

g. Upacara sangiang terdapat 11 simbol, yaitu 7 simbol verbal, dan 4 simbol nonverbal

h. Upacara manetek pantan terdapat 6 simbol, 5 nonverbal dan 1 simbol verbal

i. Upacara mamapas lewu terdapat 7 simbol yang terdiri dari 5 simbol nonverbal dan 2 simbol verbal

j. Upacara laluhan terdapat 6 simbol yang terdiri dari 5 simbol nonverbal dan 1 simbol verbal.

Dalam upacara ritual masyarakat Dayak Ngaju, ekspresi malahap(o lo lo lo kiuuu), behas (beras), meto(hewan) dan telur, ada dalam upacara apapun baik dalam upacara tiwah, upacara perkawinan, upacara mapalas/pengobatan, upacara manajah antang, upacara kehamilan, upacara sangiang dan bentuk-bentuk upacara lain berdasarkan adat Dayak Ngaju. Malahap merupakan simbol ekspresi yang diucapkan sebagai penyemangat bagi suku Dayak Ngaju. Beras dan hewan ini tidak hanya sebagai pelengkap makanan pokok namun mempunyai makna lain. Behas (beras) merupakan simbol media komunikasi yang sangat efektif antara manusia dengan Ranying Hatalla (Tuhan). Adapun darah hewan yang biasanya digunakan, yaitu babi, kerbau, dan ayam. Darah binatang ini biasanya digunakan untukmamalas atau menetralisir hal-hal yang berbau tidak baik. Darah ini melambangkan hubungan antarmakhluk, antarmanusia dan fungsinya untuk mendinginkan atau menetralisir, sedangkan telur dalam setiap upacara adat adalah lambang hubungan antarmakhluk juga sebagai simbol kedamaian dan ketentraman (Kuenna, 2015).

$$
\text { Mamapas lewu adalah }
$$

"membersihkan desa dengan cara ritual dari segala hal yang sifatnya tidak baik sehingga berdampak kepada masyarakat setempat" (Uddie, 2016) (Nurgiansah, 2021a). Mamapas lewu dilakukan karena adanya suatu peristiwa atau kejadian yang berhubungan dengan pembunuhan, ancaman keselamatan atau kejadian ditimpa musibah penyakit yang menimpa seluruh penduduk kampung atau kota, bisa juga sebagai pembayaran hajat, (niat hajat jika keinginan tercapai), hal ini dilakukan karena adanya kepercayaan dan keyakinan bahwa penduduk setempat dapat terhindar dari berbagai gangguan, ancaman, malapetaka, penyakit dan sebagainya.

$$
\text { Kegiatan ini bertujuan untuk }
$$
membersihkan alam dan lingkungan hidup (petak danum) beserta segala isinya dari berbagai, marabahaya, sial wabah penyakit, (rutas pali), untuk menciptakan suasana panas menjadi dingin, gerah menjadi sejuk. Tujuan lain dari mamapas 
lewu atau membersihkan suatu daerah/desa bertujuan agar dijauhkan dari bahaya dan celaka, agar diberikan keberuntungan dan berkat, umur panjang, rejeki yang melimpah serta ketentraman lahir batin kepada seluruh penduduk setempat.Intinya, upacara adat/ritual ini dilakukan sebagai ucapan syukur pada penguasa alam semesta, Tuhan yang maha Esa atas penyertaan dan perlindungan-Nya selama bertahun - tahun yang sudah dilalui.

Upacara ini juga dapat berkonotasi doa yang dipanjatkan kepada Sang Maha pencipta agar terciptanya kehidupan yang abadi dimuka bumi ini, terhindar dari segala musibah, pertikaian, iri dan dengki, sehingga terciptanya kerukunan dan keharmonisan hidup antar sesama umat manusia dan alam lingkungannya, saling mengasihi, saling menghormati, dan saling menghargai antar sesama.

Pelaksanaan Upacara Mamapas Lewu sering mengikutsertakan Tokoh dan kelompok agama lain. Upacara mamapas lewu ini tidak dilakukan oleh perorangan tapi oleh seluruh Masyarakat dan juga untuk pembiayaan ditanggung bersamasama.

Sejak zaman dahulu, pelaksanaan upacara adat atau ritual adat ini dilaksanakan oleh para Basir/Balian yaitu orang tertentu yang mempunyai kemampuan untuk berhubungan dengan roh-roh gaib penjaga alam, yang menurut keyakinan mereka adalah pelindung. Dalam berkomunikasi dengan menggunakan bahasa Sangiang (Munawaroh, 2013).

\section{METODE PENELITIAN}

Lokasi penelitian ini di lakukan di Kota Kasongan Kabupaten Katingan Kalimantan Tengah. Metode penelitian yang digunakan dalam penelitian ini adalah Kualitatif deskriptif. Penelitian kualitatif deskripif adalah metode penelitian yang digunakan untuk meneliti pada kondisi obyek yang alamiah dimana peneliti adalah sebagai instrument kunci. (Sugiyono, 2016), (Dewantara \& Nurgiansah, 2021)

Penelitian Kualitatif melakukan penelitian pada latar alamiah. Hal ini dilakukan karena ontologi alamiah menghendaki adanya kenyataan kenyataan sebagai keutuhan yang tidak dapat dipahami jika dipisahkan dari konteknya. (Meleong, 2017).

Dalam penelitian ini, data yang diperoleh berasal dari sumber data primer dan sumber data sekunder. Teknik pengumpulan data yang digunakan dalam penelitian ini adalah dengan interview (wawancara), observasi, dokumentasi. Sedangkan untuk teknik analisis data yang digunakan dalam penelitian ini sebagaimana yang dikemukakan Milles dan Hubberman adalah, pengumpulan data (data collection), reduksi data, penyajian data, penarikan kesimpulan.

\section{HASIL PENELITIAN DAN PEMBAHASAN Hasil Penelitian}

Tujuan dari penelitian ini adalah untuk mengetahui apa saja sarana dan prasarana upacara mamapas lewu, bagaimana tata cara upacara adat mamapas lewu serta fungsi dan maknanya bagi masyarakat hindu kaharingan di Kota Kasongan Kalimantan Tengah. Setelah melakukan penelitian dan mengumpulkan data yang diperoleh melalui observasi, wawancara dan dokumentasi, maka selanjutnya peneliti menganalisis data dari hasil penelitian di Kota Kasongan Kalimantan Tengah. Adapun analisis hasil penelitian adalah sebagai berikut:

1. Sarana dan sesajen dalam upacara mamapas lewu.

a. Ayam 3 (tiga) ekor

b. Babi 1 (satu) ekor

2. (tujuh) ruas lamang, merupakan beras ketan dicampur dengan santan dimasak menggunakan bamboo. 
3. Air putih dan baram,sebagai persembahan kepada Ranying Hatalla Langit dan roh leluhur.

4. Satu buah sangku, sebagai tempat meletakkan sarana dan prasarana.

5. Dua talam (Apar-apar), tempat untuk meletakkan sesajen.

6. Satu baskom air dicampur dengan darah hewan.

7. Parepen, tempat pembakaran menyan.

8. Satu mangkok beras tawur.

9. Dawen sawang.

10. Bendera, sebagai tanpa sedang di adakan upacara adat.

11. Tampung tawar.

12. Singah Hambaruan.

13. Selendang untuk menari Riam

14. Satu buah baskom berisi kepala babi yang masih mentah, dan tujuh buah gelas berisi Malaga.

15. Mendirikan balai pundung yang terbuat dari bamboo yang digunakan untuk menyimpan penyang, benda pusaka, guci, Mandau, dan sarana mamapas.

16. Seperangkat alat musik tradisional kecapi, kangkanung, kandang, seruling dan gong.

17. Behas tampak, dilengkapi dengan sipa giling pinang, ruku tarahan, uang,

18. Tambak Hambaruan

19. Mendirikan kramat

20. Satu lembar kain digunakan untuk pelindung, tepatnya dimana pisur duduk.

21. Dua lembar kain kuning.

\section{Pembahasan}

\section{Tata cara upacara adat Mamapas Lewu}

Setelah sarana dan prasana untuk upacara Mamapas Lewu terkumpul semua, tempat telah ditentukan dan waktunya yang direncanakan telah tiba maka proses upacara Mamapas Lewu dimulai secara bertahap dengan membutuhkan waktu tiga hari. Adapun tahap - tahap pelaksanaannya sebagai berikut:
1. Sehari sebelum hari puncak pelaksanaan upacara adat mamapas lewu

Penyang - penyang dan benda benda pusaka warisan nenek moyang yang disakralkan oleh masyarakat Hindu kaharingan dituntun/dijemput dari rumah penduduk dibawa ketempat upacara Mamapas Lewu, diletakkan dibalai pandung bersama dengan guci dua buah. Masyarakat meletakkan sesajen dan sarana yang akan digunakan untuk upacara Mamapas Lewu di dekat balai Pandung. Pada malam hari Tukang rukun (rohaniawan) melaksanakan menawur memohon kehadapan Ranying Hatalla Langit untuk hadir menyaksikan upacara Mamapas Lewu dengan pekikan lo...lo...lo... sebanyak tiga kali ditambah pukulan gong sebanyak tiga kali juga. Dan memohon kehadapan Ranying Hatalla serta manivestasi beliau termasuk roh - roh penyang penjaga kampung supaya bangun yang diyakini oleh umat Hindu Kaharingan di Kota Kasongan dapat membantu masyarakat bila ada kerusuhan dan bencana yang mengancam masyarakat dikampung mereka. Kemudian disambut dan dihibur dengan tari yang disakralkan oleh umat Hindu Kaharingan yaitu tari nganjan dan tari Riam semalam suntuk.

\section{Pada Hari puncak upacara mamapas lewu}

Jika semua sudah lengkap dan siap maka Basir (Rohaniawan) memulai upacara dengan rentetan sebagai berikut:

a. Masyarakat Hindu Kaharingan di Kota Kasongan berkumpul di tempat Upacara Mamapas Lewu untuk melaksanakan pemotongan hewan kurban ayam, babi dan sapi yang didahului dengan doa oleh pemimpin upacara. Darah hewan kurban di ambil sedikit dicampur kedalam baskom yang sudah di isi air dan kayu katabah, dilanjutkan dengan menawur dan mamapas dengan mencipratkan air campuran di atas 
dengan daun papas yang dibuat dari daun kayu posi, daun sawang, daun kakujung, daun bungi, dan daun tawa. Dengan menggunakan tangan kiri terlebih dahulu kemudian diganti dengan tangan kanan. Diawali dari tempat upacara manyanggar dilanjutkan mamapas keliling kampung dan mamapas ditempat mendirikan kramat di dekat Balai Basarah Hindu Kaharingan di Kota Kasongan.Tujuannya untuk menyuruh iblis /buta Kala/ makluk yang jahat pindah dari kampung agar tidak mengganggu kehidupan manusia.

b. Binatang kurban yang telah dipotong dibiarkan sedikit yang mentah terutama daging babi yang lainnya dimasak oleh anggota masyarakat untuk sesajen dan dijadikan menu makan bersama oleh masyarakat yag hadir pada upacara Mamapas Lewu.

c. Pada siang hari setelah olahan binatang kurban masak, pemimpin upacara bersama anggota masyarakat menyiapkan sesajen yang akan dipersembahkan kepada Tuhan Yang Maha Esa/ Ranying Hatalla langit. Sesajen yang akan dipersembahkan disebut pakanan menurut masyarakat setempat. Setelah sesajen siap ditata/diatur maka pemimpin upacara yang berjumlah 3 orang duduk diatas gong berdoa sambil menawur menghaturkan/mempersembahkan sesajen kepada Ranyin Hatalla langit yang diundang hadir pada upacara tersebut. Dengan disambut tari sakral Riam panjang dan tari nganjan diiringi musik tradisional. Kemudian salah satu tokoh agama Hindu Kaharingan pergi kesungai dekat upacara Mamapas Lewu berlangsung membawa satu buah ancak yang lengkap diisi nasi, lauk pauk mentah dan masak, telor kampung, Malaga dipersembahkan kepada Jata dengan maksud memohon air suci untuk tamping tawar (tirta) sedangkan ancak yang lainnya dipersembahkan kepada penjaga kampung dihilir, dihulu seberang dan dikramat. Setelah tukang rukun mengantarkan persembahan sesajen di tempat upacara Mamapas Lewu dilanjutkan mempersembahkan sesajen di kramat bersama anggota masyarakat untuk memeriahkan upacara Mamapas Lewu. Upacara dikramat dipimpin oleh dua orang basir dengan diiringi alunan musik tradisional dan tari nganjan mengelilingi kramat oleh masyarakat yang hadir pada upacara tersebut. Seusai upacara dikramat seluruh masyarakat kembali ketempat upacara Mamapas Lewu untuk makan bersama.

3. Sehari setelah upacara Mamapas Lewu dilaksanakan pembongkaran balai pandung dan mengembalikan penyang penyang serta benda pusaka kepada pemiliknya.

\section{Fungsi dan makna upacara mamapas lewu}

\section{Fungsi Upacara Mamapas Lewu}

Upacara Mamapas lewu sebagai tindakan ritual yang mempunyai fungsi religious untuk memuja Tuhan (Ranying Hatalla Langit) serta dengan manifestasi Beliau karena telah menjaga dan memelihara alam ini dan segala isinya. Upacara Mamapas Lewu dengan menggunakan berbagai sarana bersifat sakral dan kaya akan simbol.

Sarana yang digunakan dan upacara yang dilaksanakan oleh masyarakat Hindu Kaharingan merupakan simbol rasa cinta kasih dan bakti untuk memuja Tuhan (Ranying Hatalla Langit) serta leluhur untuk mencapai kesucian.

Upacara Mamapas Lewu dilakukan untuk menetralisir membersihkan dan menyucikan alam (kampung) termasuk manusia dari pengaruh - pengaruh yang 
tidak baik agar mereka mendapatkan keselamatan, keharmonisan dan kesejahteraan dalam menjalankan kehidupannya.

\section{Makna Upacara Mamapas Lewu}

Adanya keyakinan dalam suatu religi dalam pikiran dan gagasan manusia yang menyangkut keyakinan tentang adanya: Tuhan, didunia akhirat, kekuatan sakti, roh-roh nenek moyang dan makluk makluk /roh - roh halus yang bersifat baik atau pun bersifat buruk.Keyakinan itu timbul karena memaknai ketuhanan, bahwa Tuhanlah sebagai awal dan akhir dari segala yang ada didunia ini. Dengan adanya keyakinan seperti tersebut di atas maka masyarakat Hindu Kaharingan di kota Kasongan melaksanakan upacara.

Upacara Mamapas lewu dilaksanakan dengan makna membersihkan dan menyucikan tempat, alam, kampung termasuk masyarakat yang tinggal di kampung itu dari pengaruh - pengaruh buruk yang disebabkan oleh bhuta kala (Makhluk halus yang bersifat jahat) serta menetralisir sifat - sifat buruk yang ada padanya. Kemudian diharapkan sifat - sifat baik muncul yang memiliki kekuatan yang berguna untuk kesejahteraan manusia dan alam lingkungan.

\section{KESIMPULAN}

Upacara adat Mamapas Lewu adalah bentuk dari pengimplementasian ajaran agama Hindu Kaharingan dalam mewujudkan rasa hormat, dan terima kasih kepada Tuhan (Ranying Hatalla Langit) serta roh leluhur penjaga kampung. Fungsi upacara Mamapas Lewu adalah untuk memuja Tuhan (Ranying Hatalla Langit) karena telah menjaga alam ini dan segala isinya. Upacara Mamapas Lewu dilakukan untuk menetralisir membersihkan dan menyucikan alam (kampung) termasuk manusia dari pengaruh - pengaruh yang tidak baik agar mereka mendapatkan keselamatan, keharmonisan dan kesejahteraan dalam menjalankan kehidupannya.

Upacara Mamapas Lewu bermakna untuk membersihkan dan menyucikan alam/Kampung dari pengaruh - pengaruh roh gaib yang buruk agar tercipta kondisi yang damai, sejahtera, serta keselamatan bagi seluruh umat manusia.

Penulis berharap agar kebudayaan kebudayaan yang ada dikalimantan Tengah terkhususnya upacara adat harus selalu dilestarikan karena ini adalah warisan turun temurun dari nenek moyang yang harus kita jaga sampai kapan pun. Penulis juga berharap proposal yang di buat ini dapat bermanfaat baik dari segi akademis, teoritis maupun kebudayaan, Penulis menyadari proposal yang di buat ini masih jauh dari kata sempurna oleh karena itu Penulis mengharapkan kritik dan saran bagi para pembaca.

\section{DAFTAR PUSTAKA}

Dewantara, J. A., \& Nurgiansah, T. H. (2021). Building Tolerance Attitudes Of PPKN Students Through Multicultural Education Courses. Jurnal Etika Demokrasi, 6(1), 103-115.

Iper. 1999. Pengertian Suku Dayak. UAJY

Kuenna. 2015. Simbol Dalam Upacara Adat Dayak Ngaju. Jurnal, Bahasa, Sastra, dan Pembelajaran. Juni 2021

Moleong. 2017. Metodelogi Penelitian Kualitatif. Penerbit : PT.Remaja Rosdakarya : Bandung Nurgiansah, T. H. (2020). Filsafat Pendidikan. In Banyumas: CV Pena Persada.

Nurgiansah, T. H. (2021a). Partisipasi Politik Masyarakat Sleman di Masa Pandemi Covid-19

dalam Konteks Pendidikan Kewarganegaraan. Jurnal Civic Hukum, 6(1), 1-9.

Nurgiansah, T. H. (2021b). Pendidikan Pancasila. In Solok: CV Mitra Cendekia Media. 
S, Munawaroh. 2013. Upacara Adat Mamapas Lewu. Jantra. Juni 2021

Rogate, A. 2016. Perspektif Masyarakat Terhadap Upacara Mamapas Lewu. Pendidikan Agama Hindu. Juni 2021

Sugiyono. 2016. Metode Penelitian Kualitatif. Juni 2021

Udie, P. 2016. Upacara Mamapas Lewu Pada Masyarakat Hindu Kaharingan. Bawi Ayah. Juni 2021 